Nursing

Philosophy

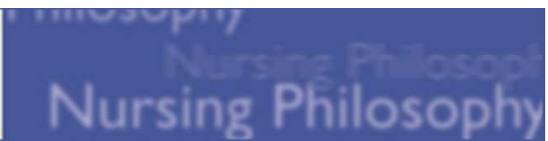

\title{
Evaluating Realist Evaluation: A response to Pawson's reply
}

\begin{tabular}{|r|l|}
\hline Journal: & Nursing Philosophy \\
\hline Manuscript ID & Draft \\
\hline Manuscript Type: & Dialogue Contribution \\
\hline Keywords: & Philosophy of Science, Nursing Research, Realism \\
\hline \multicolumn{2}{|}{} \\
\hline
\end{tabular}

\section{SCHOLARONE $^{\text {m }}$}

Manuscripts 


\section{Evaluating Realist Evaluation: A response to Pawson's reply}

I am very grateful for this opportunity to respond to Ray Pawson's (2016a) reply to my immanent critique of realist evaluation (Porter 2015a). To aid comparison, my response follows the headings and structure of Pawson's reply.

Let me start on a positive note of unambiguous agreement. I entirely concur with Pawson's position in the first section of his reply that research methodology involves a reciprocal relationship between principles and practice. However ...

The main thrust of his argument in this section involves an attempt to contrast the grounded methodologist rooted in the practicalities of research (Pawson) with the rootless theorist obsessed with disconnected doctrines (Porter). Unsurprisingly, I do not accept this characterisation.

As a general observation, all research, whether explicitly or implicitly, is founded on ontological, epistemological and axiological assumptions. If those assumptions are confused or contradictory, then this is likely to have deleterious consequences for the practical conduct of research. Theoretical efforts to clear confusions and contradictions are therefore a legitimate component of the research process. 
More specifically, while I respect Pawson's aspiration to drive realism into research practice (Pawson and Tilley, 1997), in his efforts to do so he has never shied away from pontificating on matters philosophical. I assume this is because he accepts that Realist Evaluation (RE) requires a cogent theoretical foundation. But whatever his motivation, the fact remains that he has frequently presented readers with ontological, epistemological and axiological arguments, so he can hardly complain when they are subjected to scrutiny.

Conversely, his assertion that 'not a jot, not an iota of the empirical work is discernable within Porter's fragmentary "deconstructions"' (134) is simply false. Each of the three main sections of my paper includes an illustrative discussion of empirical RE that I have engaged in. His accusation that my critique fails to interweave principle and practice has no merit.

Pawson's attempt to rule my arguments out of court because of the terrain I place them on is a dangerous ploy. As he observes, 'an obstinate method which fails to learn will ossify or die' (133). May I suggest that, in his reluctance to countenance critical analysis of RE because it addresses ontological and axiological issues, it is Pawson rather than me who is displaying obstinacy? As will be seen, his distain for my supposed pretence to philosophical perfection, combined with his persistent tendency to use argumentative gambits of dubious pertinence, means that he rarely engages directly with the substance of my arguments. This is unfortunate because it is through such engagement that we can all learn. 


\section{Instrumentalism?}

This section begins with Pawson complaining that in citing his use of the value-laden terms 'poor performance' and 'inappropriate behaviour' in his explanation of the origins of interventions, I 'do not even bother to mention that the research in question [from whence he states these terms are taken] is a review of so-called naming-and-shaming programmes' (134). The reason why I didn't mention it is not because I couldn't be bothered but because there is absolutely no indication in his text that this is the origin of his statement, not even a citation. All there is is a bald didactic pronouncement that I treated as such.

In response, he argues that the use of ostensive definition in his invisible review means that my 'stricture on conceptual exactitude misses the point' (134). I have no idea what stricture on conceptual exactitude he is talking about. I wasn't concerned with the exactness or otherwise of these concepts. What interested me was their expression of values and how researchers might choose to approach those values.

He goes on to provide a clear explanation of the contingencies that characterise the causal chains involved in policy initiatives, concluding that 'outcomes, by and large, are at variance with policy expectation. In short there are no givens here' (134). I am happy to acknowledge the important insight that the outcomes resulting from interventions should never be taken as givens, but those were not the 'givens' that my argument related to. Instead, I was pointing to the danger of researchers taking the value judgements of 
policy makers ('poor performance', 'inappropriate behaviour') as givens, and therefore not subjecting them to critical analysis. While internally cogent, his argument is beside the point.

\section{Facts?}

Pawson takes me to task for suggesting an affinity between his position and Weber's (1949) notion of social scientific value freedom 'whereby the scientist is mandated to take an objective, value-neutral approach to her subjects' (Porter 2015a: 248). Pawson counters this by pointing out that he has never cited and does not accept Weber's views on objectivity. But I didn't assert that he accepted Weber's position, simply that there was an affinity between the two positions. What is odd is that Pawson then goes on to confirm that affinity: 'As a matter of fact, I do believe that research should cherish the aspiration to be objective' (135).

It gets odder. In support of his contention that 'objectivity does not reside in the search for facts' (135), he uses an example that assumes three facts:
A job creation scheme may be regarded as a 'success' as measured by significant recruitment from the unemployed, or as a 'failure' because the jobs created are largely part-time and short-term (135).

That jobs are created and that most of them are part-time and short-term are all presented as empirically established facts. Of course, the quotation also 
indicates that their interpretation can differ widely. That's why the remit of social science includes both measurement and interpretation, and why any claim to explanatory power has to take account of both. Given these truisms, it is perplexing that Pawson has committed himself to this self-contradiction, whereby on the one hand he discounts facts, and on the other he counts them.

Taking a more sensible tack, he continues by noting that observation is always theory-laden (though not determined by theory); that data always require interpretation; and that the pursuit of objectivity is a social process (Pawson's preferred process being one that relies on the distinctly Machiavellian attributes of distrust combined with ambition). His argument is that had I been sufficiently well-read to be aware of these points, I would not have accused him of having an affinity with Weber. But this contention depends on the oxymoronic assumption that the founder of interpretive sociology didn't accept that observation is theory-laden, or that data require interpretation, or that science is a social activity. It falls on all three counts.

\author{
Values? \\ Pawson starts this section with a vigorous condemnation of emancipatory \\ approaches which he characterises as deciding a priori what the world ought \\ to be and then criticising those who depart from this view as deceitful. He \\ uses Bhaskar's (1979) adoption of the Marxist concept of false consciousness \\ as an alleged example of this.
}


I happen to agree with Bhaskar's emancipatory approach, and elsewhere have explained why (Porter, 2015b). However, I didn't make any such argument in my immanent critique. Being obliged to use my limited wordage here to deal with at least vaguely pertinent issues, I do not have the space to tackle this red herring comprehensively. This is unfortunate because Pawson (2016b) made the same argument in his reply to my paper defending critical realism (2015b), to which, despite requests to the editor of Evaluation, I have not been afforded the opportunity to respond. I mention this so that readers can appreciate that my silence in that journal is not because I have no arguments to make, but because I have not been allowed to make them.

The only comment on this distraction that I have room to make here is to scotch Pawson's implication that I regard those engaging in RE research as somehow duplicitous (that would be hypocritical to say the least, given that I have engaged in RE myself). My concern is that if an evaluation method does not include a critical stance towards the values of policy makers, there is a danger that, depending on those values and the outcomes of the interventions based on them, there may be negative consequences for people that are not picked up by the evaluators. Indeed, as I pointed out in one of my (nonexistent, according to Pawson) empirical examples, I have fallen into this trap in my time.

The values argument in my immanent critique was based not on Bhaskar, but on Andrew Sayer's (2011) thesis that all of us have concerns about our flourishing or suffering. These concerns result from a combination of 
observation, reasoning and values. Sayer argues that factual statements that describe objective needs or lacks inherently contain the inference that there is merit in responding to alleviate them. I also included Sayer's qualification that this process does not automatically mandate a particular response. Pawson takes this qualification, quotes it at length, and presents it as my prime argument, thus relieving himself of the obligation to confront the main issue.

He moves on to provide an example of how RE deals with values - his review of Megan's Law. He tells us two things about the outworking of that law. First, that it resulted in unintended consequences that varied according to the contexts into which it was introduced. Second, that different people viewed it in different ways. We have been here before, so I will repeat my acceptance that causation is rarely linear and subjective perspectives rarely homogenous. But once again, I have to question the pertinence of these insights.

Because things are complicated and subject to disagreement, we have to be very careful about how we respond to them, hence my inclusion of Sayer's codicil. However, the fact that life is complicated does not warrant us ignoring avoidable suffering, hence my inclusion of Sayer's main argument. Pawson's identification of complexity and perspectival interpretation does not directly address the issue of researchers' values, and does not amount to a good reason for abandoning evaluators' responsibilities to take people's concerns into account. 
Maybe being a nursing scholar adds to the degree to which I am sensitised to this issue, in that a pretty much universally shared assumption in nursing research and practice is that the avoidance of avoidable suffering of patients is a paramount value position. In other human sciences, matters may be less clear-cut, but that does not obviate the need to address the same principles.

\section{Change?}

Pawson charges me with misrepresenting him by asserting that RE elides social structure and agency in a manner that is similar to, and therefore shares similar problems with, Anthony Giddens' (1984) structuration theory. I do not accept the charge of misrepresentation. As evidence, I will cite seven lines of Pawson and Tilley's Realistic Evaluation (1997) which contain no less than three elisions of structure and agency under the rubric of social mechanisms, each one italicised by the authors to emphasise their importance. Had space allowed, I could have included a further three examples from the same page, as well as direct approbation of the structurationist model elsewhere in their book (1997:56).

Social mechanisms are thus about people's choices and the capacities they derive from group membership. We find the same combination of agency and structure employed generally across sociological explanation and we thus suppose that the evaluation of social programs will deploy identical explanatory forms, reaching 'down' to the layers of individual reasoning ... and 'up' to the collective resources on offer (1997:66). 
Moving on, I am gratified that Pawson commends my modification of the CMO causal configuration as potentially valuable, and hope that it lives up to that potential. However, he attaches three reservations to his commendation. The first is that some of my proposals are already contained in his model. In particular, he states that in the RE model 'it is abundantly clear that contexts (C) not only pre-exist interventions but they also have causal powers' (137). In places it is indeed clear, and I pointed this out in my paper. My problem with RE is that in other places a very different conception of contexts is posited, which sees them as passive sets of circumstances rather than combinations of causal mechanisms. It is this contradiction that led me to propose the less ambiguous category of contextual mechanisms (CM).

I concur with Pawson's second reservation that using formulae runs the risk of encouraging overly mechanical interpretations. My excuse for doing so is that I was responding to the pre-existing categorical construct of context + mechanism = outcome which, for good or ill, has become the signature motif of RE.

His third reservation is based on the observation that the evaluator's task is to address the particular dynamics of the specific social situation being researched, a task that requires flexibility and imagination. I agree. But he then states that 'no amount of conceptual musing can help in this, the vital task' (137). The smokescreen of sarcasm that follows this statement fails to hide its weakness. If he had said that no amount of conceptual musing can 
replace this vital task, I would wholeheartedly agree with him. But I simply cannot accept that researchers, in their efforts to get to grips with concrete instances of the social world, can gain nothing from an appreciation of the kinds of processes they are addressing, the kinds of knowledge that can be gained about them, the best approaches to gain that knowledge, or indeed the purpose and consequences of their investigations. The upshot of taking Pawson's position seriously would be, at best, a radically abstracted empiricism (cf. Mills, 1959). Nor can I understand why a man who has spent a goodly part of his professional life musing on concepts such as contexts, mechanisms and outcomes with a view to helping researchers should undermine his own raison d'être in such a cavalier fashion.

But, according to Pawson, my sins are greater still. Not only do I muse on these unhelpful concepts, I also believe in their sanctity. At this point, I have to say that I am tiring of Pawson's ad hominem obfuscation, so let me make my position clear. What we have in RE is a methodological strategy for evaluation research that is backed up by ontological, epistemological and axiological positions. I believe that there are problems with some of those positions, and that some of those problems have posed difficulties for researchers. In my paper, I pointed them out, gave reasons why I thought they were problematic, and provided alternatives that I hoped would help resolve them. That's it and that's all. It isn't about 'metaphysical ordinances' (133); it isn't about Pecksniffian philosophy (134); it isn't about 'conceptual sanctity' (137); and, to anticipate his accusation in the next section, it isn't about 'slaying all philosophical opposition to perfect an ontology and epistemology' (138). It is 
simply a debate about the relative merits of two realist approaches to evaluation research; a debate that I had hoped would be conducted according to pertinent logic and evidence rather than circumvention and hyperbole.

\section{Realism?}

A large proportion of this section involves Pawson listing off a considerable number of the various realisms that are out there, and then criticising me for not including them in my discussion. In response, I wish to repeat that my interpretation of this dialogue is that it is about the relative merits of two approaches to realist research - Pawson's and mine. If this is so, nothing would be gained from pouring the likes of Platonic or Scottish Common Sense Realism into the mix. I am happy to accept that Pawson came to his approach through a process of erudite eclecticism that fused various strands of realism into the RE version. But it is the product of that fusion that I am addressing, not its antecedence. I therefore make no apology for not mentioning a 'panoply of realisms' (138) in my account. Nor do I apologise for uncovering the specific confusions and contradictions embedded in the RE approach.

In Pawson's final remarks, we are back once again to the parodic contrast between his pragmatism and my absolutism. I concur with his observation that:

Wise researchers begin with a broad attachment to a paradigm, select a subset of protocols most pertinent to the scope of their enquiry and then 
translate them into a research design to fit the problem under investigation (Pawson, 2016a: 138-9).

But once again, I have to object to his caricature of my supposedly contrary position. This time his accusation is that, in contrast to the sensible and modest approach quoted above, my quest is for 'realist purity' (139). Let me repeat, I have no interest in the patently futile task of trying to create some sort of metatheoretical apotheosis from which no deviation is permitted and beyond which no improvement is required. Like Pawson, I accept that researchers have to cut their methodological coat according to their investigative cloth; like Pawson, I take epistemological labour to be evolutionary. I locate this dialogue in that evolutionary process.

The important issue is not my irritation with the accusation that I hold a ridiculous belief in the incorrigibility of a social theory, but that acceptance of such an accusation closes down the debate. In contrast, I want to keep the debate open, and recognise the importance of others interrogating my claims to test the degree to which they are sustainable. I can think of at least four important questions that might be asked: To what extent are my claims about the inconsistencies and contradictions of the RE model justified? If there are inconsistencies, is there a risk that they will have a detrimental effect on the prosecution of practical research? Are the alternatives I pose likely to improve matters? Are there better ways to deal with the issues I raise? On the answers to these questions my arguments stand or fall. 
My disappointment with Pawson's reply is that, for the most part, he chose not to take this sort of approach. Rather than concentrating directly on the merits or demerits of my arguments, he decided to take the route of diversion, conjecture and disparaging imputation. In turn, rather than getting to the nub of the matter, I have had to use my response to point out the diversions, refute the conjectures and rebuff the disparagements. Pawson's avoidance of issues of substance means that the dialogue between us hasn't really moved the debate on very much. Unless, that is, we make the reasonable inference that his substantive silence gives grudging consent. 


\section{References}

Bhaskar R. (1979) The Possibility of Naturalism: a philosophical critique of the contemporary human sciences. Harvester Press, Brighton.

Giddens A. (1984) The Constitution of Society. Polity Press, Cambridge.

Mills C.W. (1959) The Sociological Imagination. Oxford University Press, Oxford

Pawson R. (2016a) Realist evaluation caricatured: a reply to Porter. Nursing Philosophy, 17(2), 132-139.

Pawson R. (2016b) The ersatz realism of critical realism: a reply to Porter. Evaluation, 22(1), 49-57.

Pawson R. \& Tilley N. (1997) Realist Evaluation. Sage, London.

Porter S. (2015a) Realist evaluation: an immanent critique. Nursing Philosophy, 16(4), 18-28.

Porter S. (2015b) The uncritical realism of realist evaluation. Evaluation, 21(1), 65-82.

Sayer A. (2011) Why Things Matter to People: social science, values and ethical life. Cambridge University Press, Cambridge. 


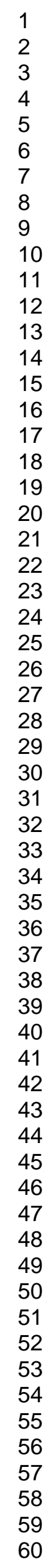

Weber, M. (1949) From Max Weber: essays in sociology (eds H. Gerth \& C. Mills), Oxford University Press, Oxford. 